\title{
Sequential Loss of Two Neighboring Exons of the Tropoelastin Gene During Primate Evolution
}

\author{
Zoltán Szabó, ${ }^{1}$ Simona A. Levi-Minzi, ${ }^{1}$ Angela M. Christiano, ${ }^{1, *}$ Carole Struminger, ${ }^{1}$ Mark Stoneking, ${ }^{2}$ \\ Mark A. Batzer, ${ }^{3}$ Charles D. Boyd ${ }^{1}$ \\ ${ }^{1}$ Pacific Biomedical Research Center, University of Hawaii, Honolulu, HI 96822, USA \\ ${ }^{2}$ Department of Anthropology, Pennsylvania State University, University Park, PA 16802, USA \\ ${ }^{3}$ Department of Pathology, Stanley S. Scott Cancer Center, Neuroscience Center of Excellence, Louisiana State University Medical Center, \\ New Orleans, LA 70112, USA
}

Received: 6 July 1998 / Accepted: 18 February 1999

\begin{abstract}
Previous evidence has demonstrated the absence of exons 34 and 35 within the $3^{\prime}$ end of the human tropoelastin (ELN) gene. These exons encode conserved polypeptide domains within tropoelastin and are found in the ELN gene in vertebrate species ranging from chickens to rats to cows. We have analyzed the ELN gene in a variety of primate species to determine whether the absence of exons 34 and 35 in humans either is due to allelic variation within the human population or is a general characteristic of the Primates order. An analysis of the $3^{\prime}$ end of the ELN gene in several nonhuman primates and in 546 chromosomes from humans of varying ethnic background demonstrated a sequential loss of exons 34 and 35 during primate evolution. The loss of exon 35 occurred at least 35-45 million years ago, when $\mathrm{Ca}$ tarrhines diverged from Platyrrhines (New World monkeys). Exon 34 loss, in contrast, occurred only about 6-8 million years ago, when Homo separated from the common ancestor shared with chimpanzees and gorillas. Loss of both exons was probably facilitated by Alu-mediated recombination events and possibly conferred a functional evolutionary advantage in elastic tissue.
\end{abstract}

\footnotetext{
* Present address: Department of Dermatology, Presbyterian Medical Center, Columbia University, New York, NY 10027, USA

Correspondence to: Charles D. Boyd; e-mail: cbkc08901@aol.com
}

Key words: Tropoelastin gene - Alu repeat sequences - Gene evolution

\section{Introduction}

Elastic fibers are extracellular matrix structures that confer the property of resilience and elastic recoil to all elastic tissues (Sandberg et al. 1969). Elastin is the major protein component of elastic fibers (Rucker et al. 1973). Extensively cross-linked and highly insoluble, elastin is assembled from a family of precursor proteins collectively referred to as tropoelastin (Sandberg et al. 1969; Rucker et al. 1973; Foster et al. 1975). Tropoelastins (ELN) are multidomained proteins composed predominantly of several hydrophobic regions rich in glycine, valine, and proline (Foster et al. 1973a) and multiple lysine-containing alanine-rich domains (Foster et al. 1973b) that serve as a substrate for the catalysis of lysine-derived cross-links by the enzyme lysyl oxidase (Kagan and Trackman 1991). A single-copy multiexon gene is responsible for the synthesis of multiple isoforms of tropoelastin by extensive alternate usage of several exons encoding both hydrophobic domains and lysinecontaining cross-link regions (Boyd et al. 1993).

In recent years, a number of investigators have char- 
acterized the structure of the gene coding for tropoelastin from several species including humans, cows, and rats (Bashir et al. 1989; Raju and Anwar 1987; Pierce et al. 1990). This analysis has revealed a gene that, in most species, is composed of 36 exons distributed throughout approximately 40,000 bp of genomic DNA, has an intron:exon ratio of almost 19:1, and has an unusually high frequency of repetitive DNA sequences within many introns, particularly at the $3^{\prime}$ end (Indik et al. 1987).

In contrast to the bovine and rat ELN genes, the human ELN gene has only 34 exons. Several years ago Rosenbloom and co-workers reported (Bashir et al. 1989; Indik et al. 1987) the absence of two exons at the $3^{\prime}$ end of the human ELN gene (exons 34 and 35). These authors suggested that the abundance of Alu repetitive DNA sequence elements surrounding exons 33 and 36 may have been responsible for the loss of exons 34 and 35 in the human ELN gene. These two exons are present within the tropoelastin gene in all vertebrate species analyzed to date and also encode highly conserved crosslink and hydrophobic regions (Boyd et al. 1991). To explore the possibility that Alu-mediated recombination events may indeed have contributed to the loss of exons 34 and 35, either within the human population or elsewhere within the primate order, we have analyzed the $3^{\prime}$ end of the ELN gene within the human population and in several other primate species. Here we report the sequential loss of exons 34 and 35 within the tropoelastin gene during primate evolution and suggest that these evolutionary changes within the ELN gene may be functionally important within primate phylogeny.

\section{Materials and Methods}

\section{Isolation of the Baboon Tropoelastin cDNA and Genomic DNA Recombinants}

A $\lambda$ gt1 1 cDNA library (kindly provided by Dr. A.W. Clowes, Department of Surgery, University of Washington, Seattle) was constructed using poly $\left(\mathrm{A}^{+}\right)$RNA from cultured baboon smooth muscle cells. Plaque forming units (pfus; $5 \times 10^{4}$ ) were screened with a previously characterized human tropoelastin cDNA, H-11 (Olson et al. 1995), using a standard screening procedure (Sambrook et al. 1989). DNA from autoradiographically positive plaque recombinants, obtained after screening primary and secondary positives, was subject to dideoxy DNA sequence analysis.

A baboon tropoelastin cDNA (BEL8) was used to screen a partial Sau3AI baboon genomic DNA library prepared using the $\lambda$ DASH II cloning vector and supplied by Clonetech. pfus $\left(5 \times 10^{4}\right)$ were screened and autoradiographically positive recombinants were also characterized by restriction enzyme analysis and DNA sequencing.

\section{Human and Primate Genomic DNA Preparations}

Genomic DNA was isolated from aliquots of blood from 53 unrelated primates using a previously described procedure (Sambrook et al. 1989). Aliquots of blood were provided by the San Diego Zoo and were obtained from the following species (the number of individual primates from which blood was obtained is indicated in parentheses): Pan troglodytes — chimpanzee (3); Gorilla gorilla—gorilla (2); Pongo pygmaeus —orangutan (2); Hylobates lar-gibbon (3); Papio cynocephalus anubis-olive baboon (12); Papio cynocephalus cynocephalusyellow baboon (12); Papio cynocephalus hamadryas-hamadryas baboon (12); Madrillus sphinx —-mandrill (3); Macacus rhesus - rhesus monkey (3); and Macacus cyanomegalus_cyanomegalus monkey (2).

Human genomic DNA was isolated from aliquots of blood from 273 unrelated individuals representing the following ethnic and geographical groups (the number of individuals from which blood was obtained is also indicated in parentheses): African Americans (50), Hispanic Americans (50), Caucasian Americans (76), Hungarians (46), Zaire pygmies (10), Central African Republic pygmies (7), Indonesian Rotis (1), Indonesian Ternates (4), Indonesian Hiris (5), Papua New Guinea-highland region (10), and Papua New Guinea—coastal region (14).

\section{PCR Analysis of the 3' End of the Human and Primate Tropoelastin Genes}

PCR analysis of human genomic DNA was carried out in a $25-\mu 1$ volume containing intron specific primers derived from intron $33\left(5^{\prime}\right.$ AAC ACA GGG AAC ATT TGC TTT $3^{\prime}$ ) and intron 36 (5' CCT CTC AGT TTC GGC TCT AAT 3'), $67 \mathrm{~m} M$ Tris- $\mathrm{HCl}(\mathrm{pH} 8.3), 16.6 \mathrm{~m} M$ $\left(\mathrm{NH}_{4}\right)_{2} \mathrm{SO}_{2}, 10 \mathrm{~m} M$ 2-mercaptoethanol, $1.5 \mathrm{mM} \mathrm{MgCl} 2,10 \%$ DMSO, $0.625 \mathrm{U}$ AmpliTaq polymerase, and $100 \mathrm{ng}$ genomic DNA. Following a 3-min incubation at $94^{\circ} \mathrm{C}$, reactions were incubated for 34 cycles, each cycle consisting of a denaturation step at $94^{\circ} \mathrm{C}$ for $30 \mathrm{~s}$, an annealing step at $61^{\circ} \mathrm{C}$ for $30 \mathrm{~s}$, and an extension step at $72^{\circ} \mathrm{C}$ for $75 \mathrm{~s}$.

PCR analysis of primate genomic DNA was carried out using similar incubation conditions and primers derived from exon 33 (5' GGC TTC GGA TTG TCT CCC AT $3^{\prime}$ ) and exon 34 (5' CCA ACT CCC AAG CCT CCA GC $3^{\prime}$ ) of the baboon tropoelastin gene. The reaction conditions, following a preincubation at $94^{\circ} \mathrm{C}$ for $3 \mathrm{~min}$, involved 35 cycles, and each cycle consisted of an incubation at $94^{\circ} \mathrm{C}$ for $30 \mathrm{~s}, 63^{\circ} \mathrm{C}$ for $30 \mathrm{~s}$, and $72^{\circ} \mathrm{C}$ for $15 \mathrm{~s}$. PCR products from both human and primate DNA samples were analyzed by electrophoresis through $1.2 \%$ agarose and visualized by staining with $0.5 \mu \mathrm{g} / \mathrm{ml}$ ethidium bromide.

\section{Results}

\section{The Sequence Analysis of Baboon Tropoelastin cDNAs}

Six positive individual recombinants (four of which were identical) were obtained following screening of a baboon smooth muscle cell cDNA library with a human tropoelastin cDNA. Analysis of these recombinants provided DNA sequence from the domains corresponding to exon 23 of the human ELN gene to the first polyadenylation consensus sequence in the $3^{\prime}$ untranslated region within exon 36. The nucleotide sequence corresponding to the coding domain, the derived amino acid sequence, and a comparison to the derived amino acid sequences from human, rat, and chicken are presented in Fig. 1. The baboon tropoelastin cDNA sequence, as one would expect, shows the most identity to the human sequence. Exon 34, which does not exist in human, encodes a hydrophobic domain that is identical in sequence between baboon and rat. The polypeptide domains encoded by exons 27 and 33 are identical in baboon and human; 
Baboon GCA GCT GCT AAA GCA GCC GCC AAA GCC GCC CAG TTT -..

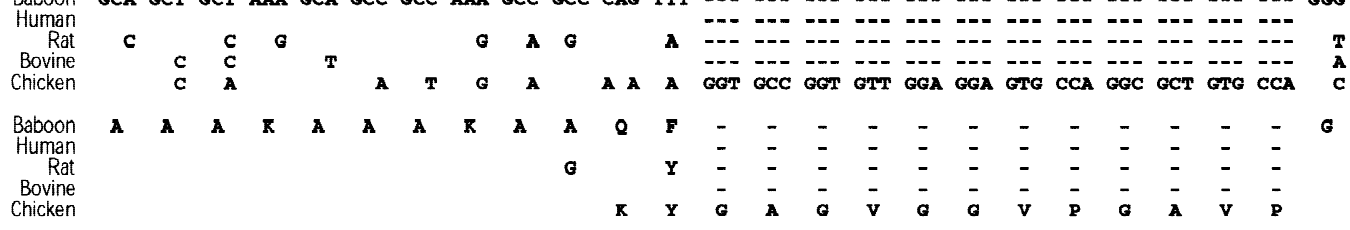

Baboon TTA GTT CCT GGT GTC GGC GTG GCT CCT GGC -.. -... GTT GGC GTG GCT CCT GGA GTC GGT GTG GCT CCT -.-

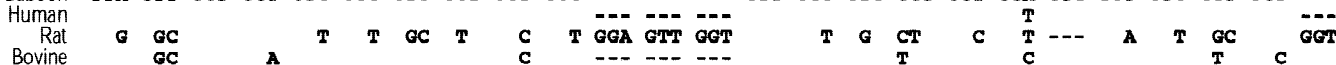

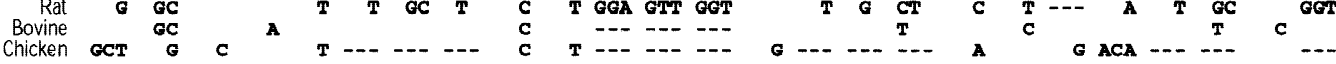

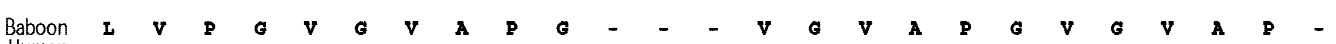
$\begin{array}{rlll}\begin{array}{c}\text { Human } \\ \text { Rat }\end{array} & \mathbf{G} & \mathbf{G} & \mathbf{v} \\ \text { Bovine } & \mathbf{G} & - & -\end{array}$

Chicken A

Baboon -- - - - - GGC GTT GGC GTG GCT CCT GGC GTP GGC GTG GCT CCT GGT GTT GGT GTG GCT CCT GGC GTT GGC GTG

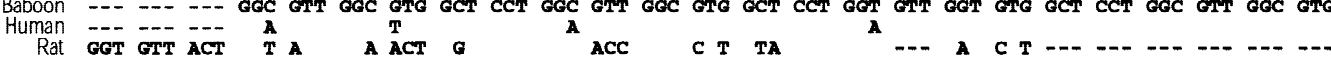

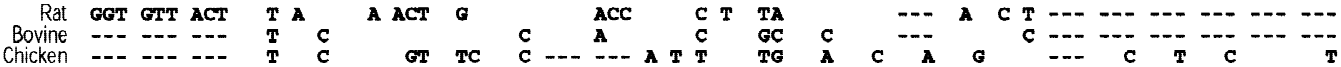

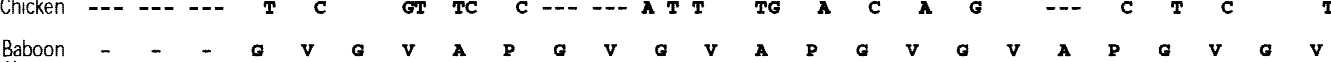

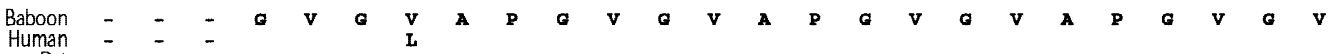

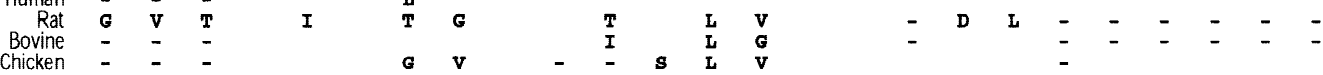

24,25

Baboon GCT CCT GGC GTT GGC ATC GGC CCT GGT GGA GTT GCA GGA GTG GGA CCC CCA GGC GCA ACC AAA TCT GCT GCC AAG
Human

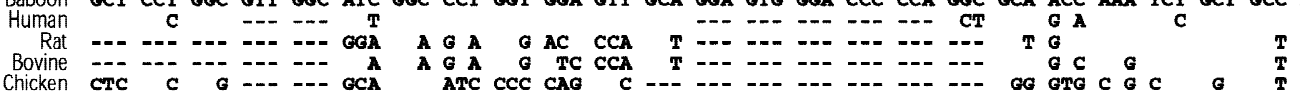

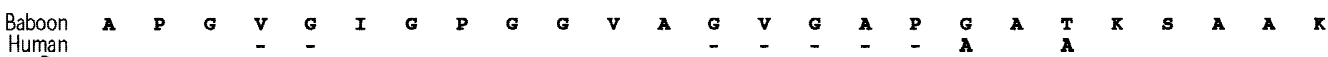

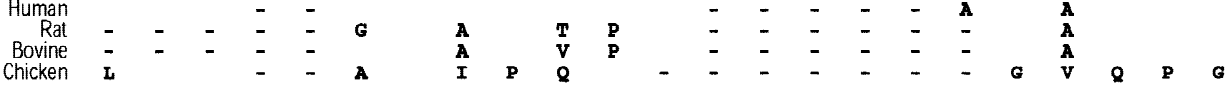

$25{ }^{26}$

Baboon GCA GCT GCC AAA GCC CAG CTC CGA GCT GCA GCT GGG CTP GGT GCT GGC ATC CCT GGA CTS GGA GTS GGT GTC GGT
Human TG

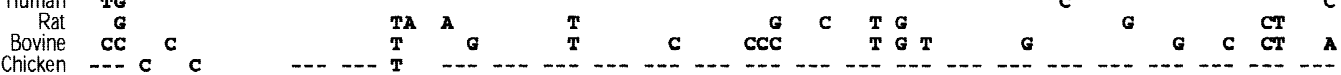
$\begin{array}{lllllllllllllllllllllllllllllll}\text { Baboon } & \mathbf{A} & \mathbf{A} & \mathbf{A} & \mathbf{K} & \mathbf{A} & \mathbf{Q} & \mathbf{L} & \mathbf{R} & \mathbf{A} & \mathbf{A} & \mathbf{A} & \mathbf{G} & \mathbf{L} & \mathbf{G} & \mathbf{A} & \mathbf{G} & \mathbf{I} & \mathbf{P} & \mathbf{G} & \mathbf{L} & \mathbf{G} & \mathbf{V} & \mathbf{G} & \mathbf{A} & \mathbf{G}\end{array}$

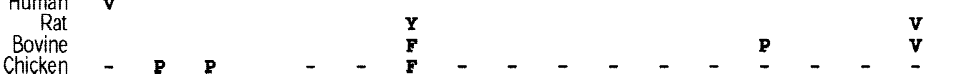

Baboon GTT CCT GGA CTT GGA GTT GGT GCT GGC GTT CCT GGG CTT GGA GMT GGT GCT GGT GTY CCT GGC TMT GEG GCA ---

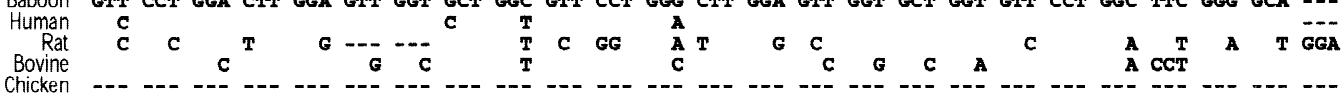

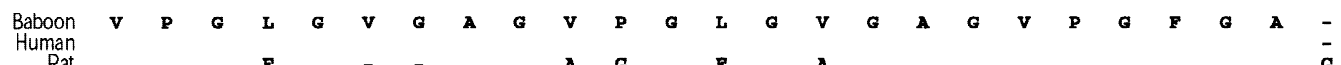

Bovine

Chicken

26,27

Baboon -- GTA CCT GGA GCC CTG GCT GCC GCT AAA GCA GCC AAA TAT GGA

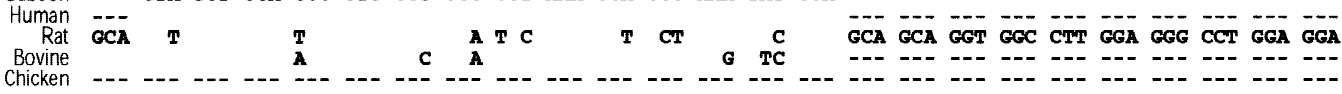

$\begin{array}{lllllllllllllllllllllllllllllll}\text { Baboon } & - & \mathbf{V} & \mathbf{P} & \mathbf{G} & \mathbf{A} & \mathbf{L} & \mathbf{A} & \mathbf{A} & \mathbf{A} & \mathbf{K} & \mathbf{A} & \mathbf{A} & \mathbf{R} & \mathbf{Y} & \mathbf{G} & \mathbf{-} & - & - & - & - & - & - & - & - & - & -\end{array}$

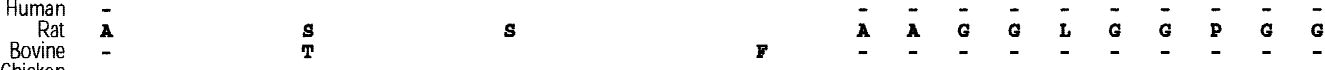

Baboon --. -- --. -- GCA GGA GTG CCT GGG GCC CTP GGA GGG CTC GGG GCT CTC GGT GGA GTA --. GGC ATC CCA GGC

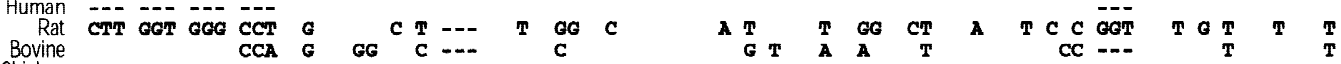

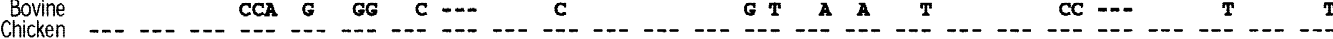

$\begin{array}{lllllllllllllllllllllllllll}\text { Baboon } & - & - & - & - & \mathbf{A} & \mathbf{G} & \mathbf{V} & \mathbf{P} & \boldsymbol{G} & \mathbf{A} & \mathbf{I} & \mathbf{G} & \mathbf{G} & \mathbf{I} & \mathbf{G} & \mathbf{A} & \mathbf{L} & \mathbf{G} & \mathbf{G} & \mathbf{V} & - & \mathbf{G} & \mathbf{I} & \mathbf{P} & \mathbf{G}\end{array}$

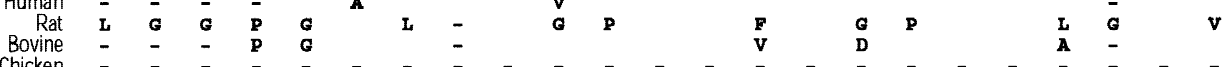

Fig. 1. Continued. 
$28 \mathbf{1}^{29}$

29,30

Baboon GGT GTG GTG GGA GCC GGA CCG GCC GCC GCC GCT GCC GCC -- AAA GCT GCT GCC AAA GCC GCC CAG TTT GGC CTA

\begin{tabular}{|c|c|c|c|c|c|c|c|c|c|c|c|c|c|c|c|c|c|c|c|c|c|c|c|c|c|}
\hline $\begin{array}{r}\text { Human } \\
\text { Rat } \\
\text { Bovine }\end{array}$ & $\mathbf{A}$ & $\mathbf{A}$ & $\begin{array}{l}\mathrm{CA} \\
\mathrm{CA}\end{array}$ & & $\begin{array}{l}\mathbf{G T} \\
\mathbf{T}\end{array}$ & $\begin{array}{l}\mathbf{C} \\
\mathbf{T}\end{array}$ & $\begin{array}{l}\mathbf{C} \\
\mathbf{T} \\
\mathbf{T}\end{array}$ & $\begin{array}{l}\mathbf{T} \\
\mathbf{T}\end{array}$ & $\mathbf{T}$ & $\begin{array}{l}\mathbf{T} \\
\mathbf{G}\end{array}$ & C & $\mathbf{T}$ & $\mathbf{A}$ & $\begin{array}{l}\text { GCC } \\
--- \\
---\end{array}$ & & & $\begin{array}{l}\text { C } \\
\text { C }\end{array}$ & $\mathbf{T}$ & G & $\mathbf{T}$ & & A & AC & $\mathbf{T}$ & \\
\hline icker & -- & -- & --- & --- & --- & --- & --- & --- & -- & --- & --- & -- & --- & --- & -- & --- & -- & --- & --- & -- & --- & --- & --- & $\mathbf{T}$ & -- \\
\hline $\begin{array}{l}\text { Baboon } \\
\text { Human } \\
\text { Rat } \\
\text { Bovine }\end{array}$ & $\mathbf{G}$ & v & $\begin{array}{l}\mathbf{V} \\
\mathbf{A} \\
\mathbf{A}\end{array}$ & G & $\begin{array}{l}\mathbf{A} \\
\mathbf{G} \\
\mathbf{V}\end{array}$ & $\begin{array}{l}\mathbf{G} \\
\mathbf{A}\end{array}$ & $\mathbf{P}$ & $\mathbf{A}$ & A & $\mathbf{A}$ & $\mathbf{A}$ & $\mathbf{A}$ & $\mathbf{A}$ & $\overline{\mathbf{A}}$ & $\mathbf{K}$ & $\mathbf{A}$ & $\mathbf{A}$ & A & $\mathbf{K}$ & A & A & $\mathbf{Q}$ & $\boldsymbol{F}$ & G & \\
\hline Chic & - & - & - & - & - & - & - & - & - & - & - & - & - & & - & - & - & - & - & - & - & - & - & & \\
\hline
\end{tabular}

Baboon GGG GGA CCT GCT GGA CTC -- GGA GTC --. -- -.- -- GGA GGA CTC GGA GTC GGA GGG CTP GGA GCC --- --

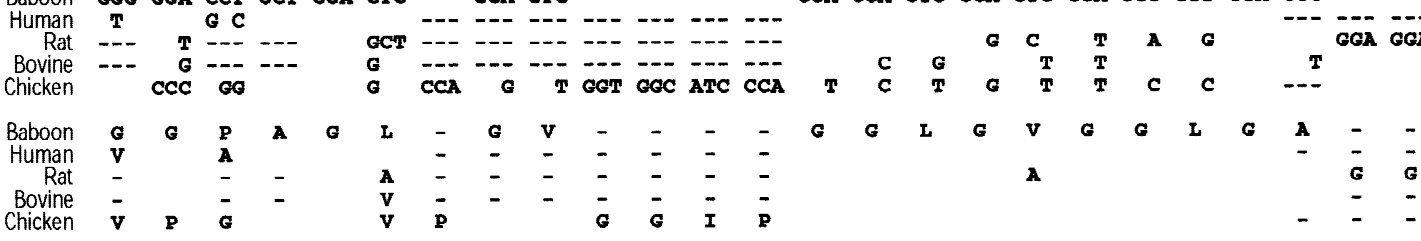

Baboon -- - -

Human

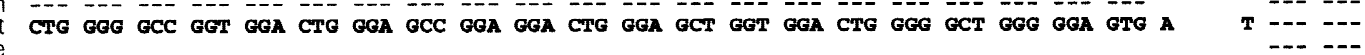

Chicken

GGT GGC CTT

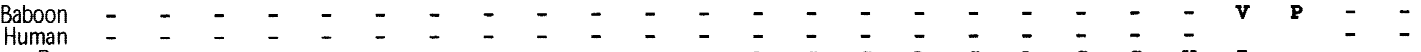

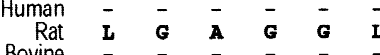

Chicken

$$
30,31
$$

Baboon GGT GTP GGG GGC CTT GGA GGT GTE TCT CCA GCT GCG GCC GCC AAA GCA GCT AAA TAC GGA --- -- -.- --- --

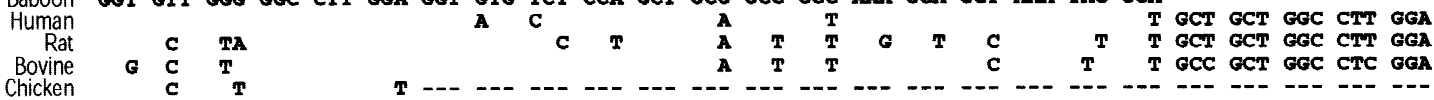

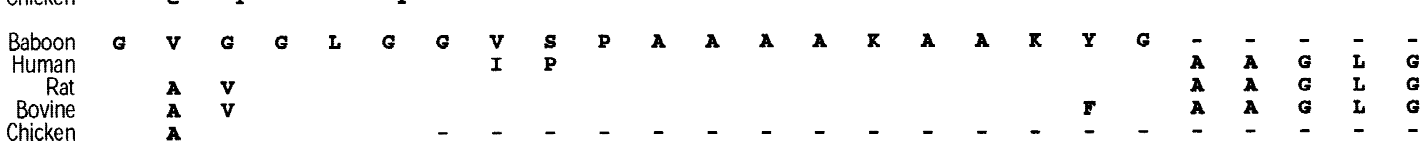
32 /33

Baboon -.- - - - Human GGT GTC CTA GGG GGT GCC GGG CAG TTC CCA CTT GGA G

Rat GGT GTC CTA GGA GCC -.. AGG CCA TTC CCA GGC GGA G

Bovine GGT GTC CTA GGA GCT GGC CAG CG TTC CCA ATT GGA G T G

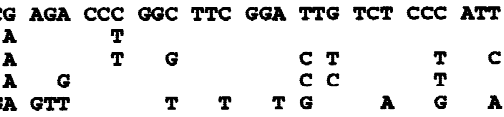

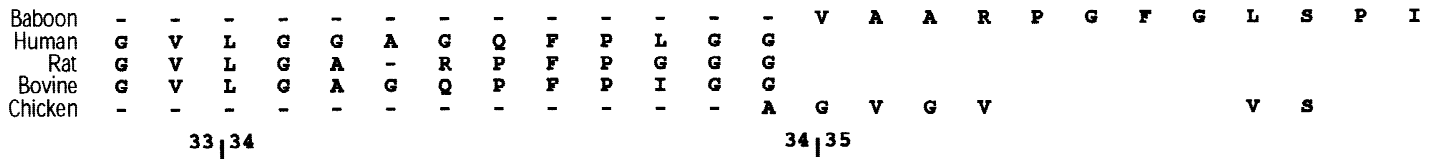

Baboon TTC CCA GET GEC GCC GCT GGA GGC -- TTG GGA GTT

Human a $\quad$ T T

$\begin{array}{lllllll}\text { Bovine } & \text { A } & & \text { G } & -- & \text { C } & \\ \text { Thicken } & T & \text { G } & \text { GT GGC AAA CCT CCC AAG CCC TTC GGA GGG GCC CTG GGA }\end{array}$

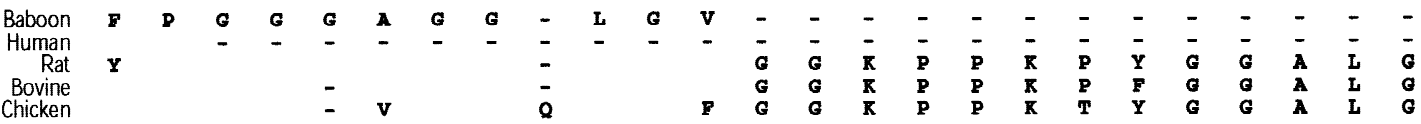

Chicken 35 I $^{36}$

Baboon -- - - - - - - GGT GGG -- GCG GCC TGC -- CTG GGG AAA TCT TGT GGC CGG AAG AGA AAA TGA

$\begin{array}{rllll}\text { Rat GCC CTG GGA TAT CAA } & \text { G } & -- & \text { T T }\end{array}$

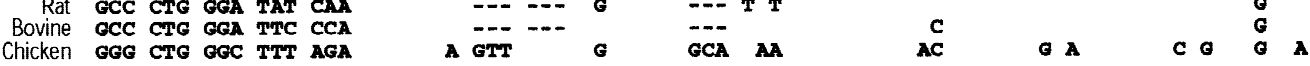

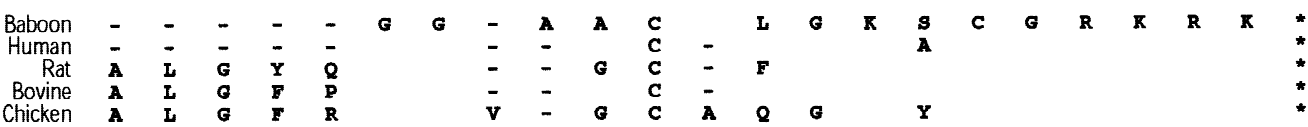

Fig. 1. Multiple alignment of the nucleic acid and the translated amino acid sequences of the ELN gene corresponding to exons 23 through 36 from different vertebrate species. Nucleic acid alignments for the five species alternate with the corresponding amino acid alignments. Bars above the nucleic acid sequence indicate exon boundaries and the numbers on either side of these bars identify the particular exons. The exon boundaries for the chicken ELN gene are inferred by comparing the chicken tropoelastin amino acid sequence to the amino acid sequence for rat, bovine, and human ELN. Sequence conservation within the exon-encoded domains known in rat, bovine, and human permitted the inferred assignment of exon-intron boundaries in the chicken ELN gene. Only the nucleic acid sequence from the baboon ELN gene is presented in full; in the comparison of this sequence to the other mammalian sequences, no designation represents an identical sequence and dashes represent lack of sequence. Note the high degree of conservation of sequence from exon 33 through exon 36 that is evident in the comparison of these domains in chicken, rat, and cow. Exon 35 is absent in the baboon sequence. Exons 34 and 35 are absent in the human sequence. 


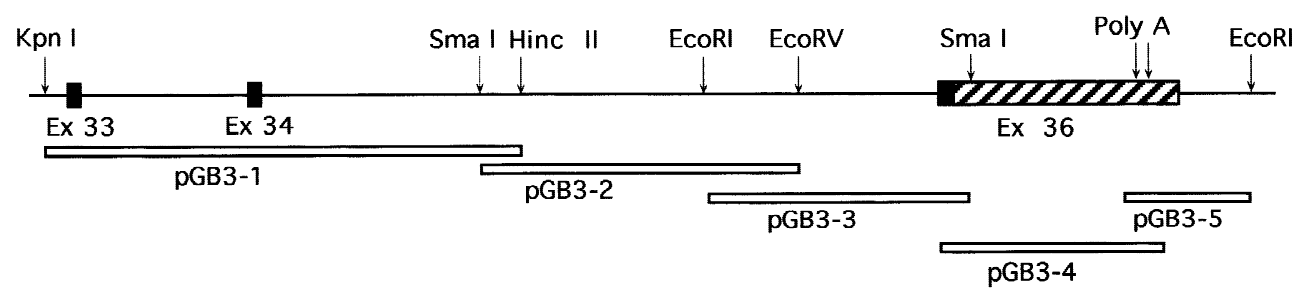

Fig. 2. Restriction map and subcloning strategy for the $\lambda$ genomic clone GB3. Filled boxes represent coding sequences within individual exons; the hatched area in exon 36 is the $3^{\prime}$ untranslated region (UTR). Arrows indicate unique restriction enzyme recognition sites as well as

there is only a single valine-to-alanine change between human and baboon in the sequence encoded by exon 26 . The sequence encoded by exon 29 in baboon lacks a single alanine preceding the first lysine compared to the human sequence. Exons 24, 25, and 30 differ the most in sequence. Similarly to humans, the elastin receptor binding hexapeptide repeating element VGVAPG is encoded seven times in exon 24 in baboons. In addition, there is a leucine-to-valine substitution in the fourth repeat and a valine and glycine insertion in the baboon sequence encoded at the end of exon 24. Five additional amino acids (GVGAP) are encoded in exon 25 in baboons and an additional alanine-to-glycine substitution creates a pentapeptide VGAPG, very similar to the repeating receptorbinding VGVAPG found in other mammals. A polar threonine also substitutes a hydrophobic alanine in the domain encoded by exon 25 . The domain encoded by the baboon exon 30 contains a valine-to-glycine and an alanine-to-proline substitution, in addition to an insertion of glycine, valine, and alanine. A valine-serine dipeptide replaces an isoleucine and proline following the first amino acid residue in exon 31. Exon 36 contains an alanine insertion and a serine-to-alanine substitution, making the $3^{\prime}$ end of the baboon tropoelastin cDNA more polar by comparison to the human sequence.

\section{The 3' End of the Baboon Tropoelastin Gene}

Baboon tropoelastin cDNA recombinants B8 and B16 were used to obtain five recombinants from a baboon genomic DNA library. Restriction and PCR analysis combined with DNA sequencing permitted the overlapping alignment of the insert DNA from these recombinants and the identification of exon and intron sequence corresponding to the $3^{\prime}$ end of the baboon tropoelastin gene. The results are summarized in Fig. 2. The 5' overlapping DNA fragments contained 5942 bp of genomic DNA sequence. The $5^{\prime}$ end of this sequence was located within intron 32. The $3^{\prime}$ end of this sequence was located immediately downstream of a second polyadenylation site within exon 36. Within this genomic DNA sequence, we were able to identify successfully intact exons 33,34 , and 36. Extensive sequence analysis revealed no evidence of an intact exon 35 within the intron separating two putative polyadenylation sites within exon 36 . The genomic clone GB3 was divided into five overlapping plasmid subclones, which are represented as shaded horizontal bars and referred to as pGB recombinants.

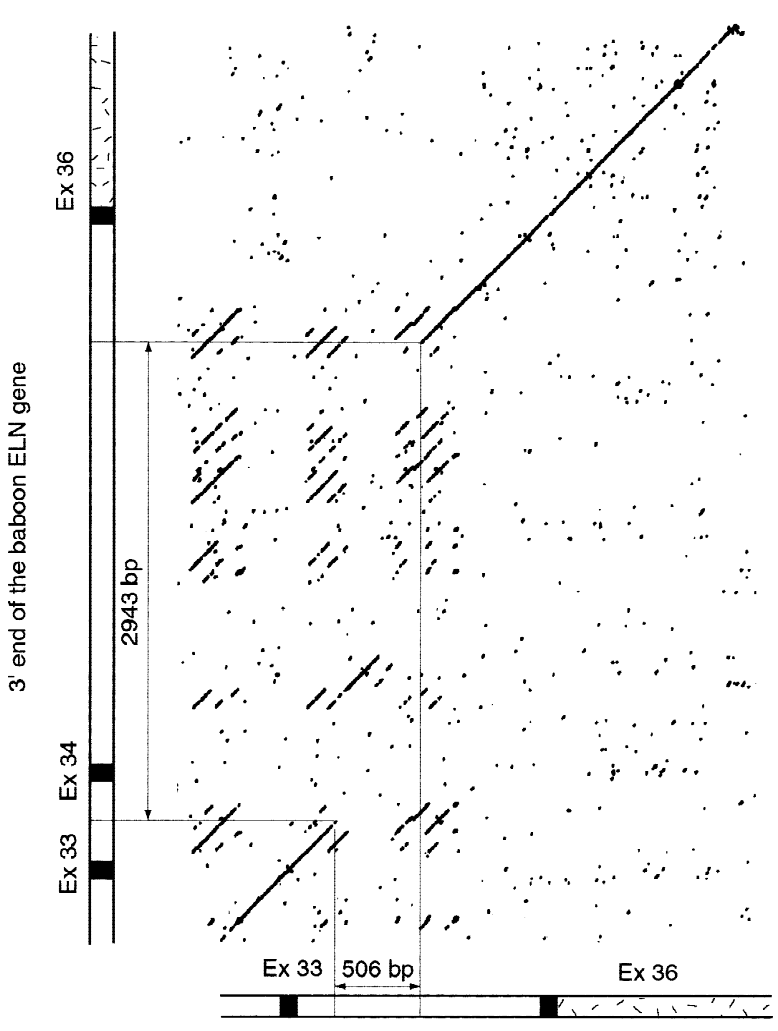

$3^{\prime}$ end of the human ELN gene

Fig. 3. A comparison of exon and intron sequence within the $3^{\prime}$ end of the human and baboon ELN genes. The $3^{\prime}$ end of the human gene and the baboon ELN gene are graphically represented and drawn to scale on the abscissa and the ordinate, respectively. Filled boxes represent coding sequences, $3^{\prime}$ UTR is represented by a hatched box. Identical nucleic acid sequences are indicated in this comparison as single dots. The dotplot chart was produced by the program Compare from the GCG software package. Diagonal lines designate matching sequences. The boxed region between the two longest diagonal lines, corresponding to $506 \mathrm{bp}$ in the human and $2943 \mathrm{bp}$ in the baboon ELN gene, represents a domain of little sequence identity. This domain contains Alu repeat elements which are represented in this comparison as short, multiple parallel lines.

exons 34 and 36. At sequence positions 2636-2671 a potential vestige of exon 35 was identified (AGGGAAACCCCCCAGCGCGTGCAAGGTGCCTGGGC), but the absence of a canonical acceptor site precluded the possibility that this intron sequence could be used as a functional exon sequence. 


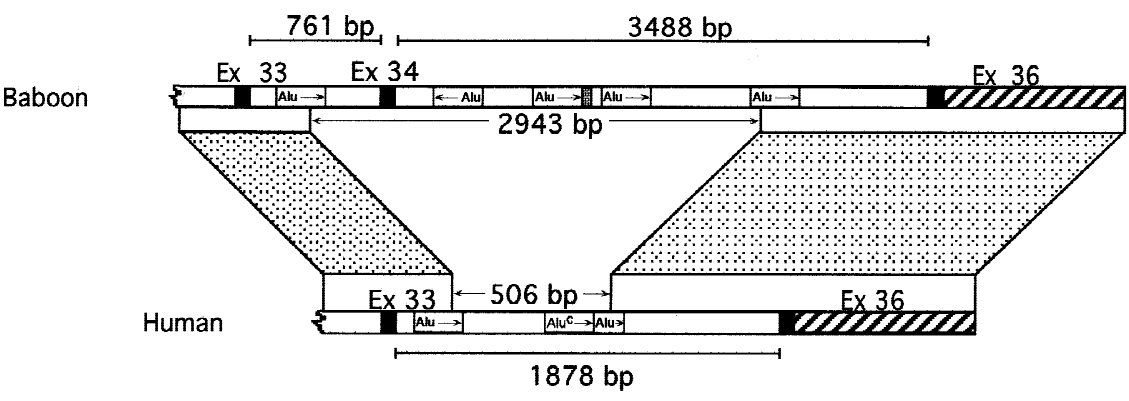

Fig. 4. A comparison of the $3^{\prime}$ end of the baboon (Papio cyanocephalus) and human (Homo sapiens) tropoelastin genes. Regions containing a high percentage of identical sequences are indicated as shaded areas, exons are represented as filled boxes. The 3' UTR in exon 36 is marked as a cross-hatched box. Distances between exons and other domains are shown as basepairs. A vestige of exon 35 is marked as () in the middle of intron 34 of the baboon ELN gene. ( $\mathrm{Alu} \rightarrow$ ) Alu repeat, $(\leftarrow$ Alu $)$ Alu repeat in reverse orientation, ( $\mathrm{Alu}^{\mathrm{c}} \rightarrow$ ) complementary sequences to the Alu repeat.
Comparison of DNA sequences from intron 32 to the $3^{\prime}$ end of exon 35 from both human and baboon ELN genes revealed the expected and extensive identity between exon 33 and exon 36 (Fig. 3). Moreover, considerable identity was also noted within the intron sequence surrounding exon 33 and the 5' region of exon 36 between both orthologues. This similarity in intron sequence ended $5^{\prime}$ of exon 34 in the baboon gene and $5^{\prime}$ of exon 36 in both the baboon and the human gene, directly within an Alu repeat sequence (Fig. 4). Between these Alu repeats, 2943 bp of DNA in the baboon gene shared only a $40 \%$ identity with the corresponding 506 bp of the human sequence, as opposed to $80 \%$ identity for the rest of the $3^{\prime}$ end. The 506-bp sequence corresponded to a complex Alu repeat structure composed of a complete Alu repeat in the reverse orientation and a right monomer in the $5^{\prime}-3^{\prime}$ orientation. The putative breakpoints themselves fall in the right half of the surrounding Alu element.

\section{PCR Analysis of the 3' End of the Primate and Human ELN Genes}

PCR primers derived from the $3^{\prime}$ end of exon 33 and the $5^{\prime}$ end of exon 36 in the human tropoelastin gene were used to generate a 1655-bp amplimer that represented the arrangement of intron 33 as previously characterized in the human gene and is presented in Fig. 5A. PCR analysis, using these intron 33 primers, of genomic DNA from 546 alleles that represented 11 diverse ethnic groups revealed no size variation in the recovery of this 1655 -bp PCR fragment (Table 1). Representative examples of the recovery of PCR-derived DNA from these human genomic samples are presented in Fig. 5B.

Similarly, a PCR assay was established from exon 33 to exon 34 in the baboon tropoelastin gene that yielded a PCR amplimer of $880 \mathrm{bp}$ (Table 1). Analysis of genomic DNA from 53 unrelated primates, ranging from gorillas to baboons to rhesus monkeys revealed a consistent recovery of a PCR derived DNA fragment of $880 \mathrm{bp}$. A representative example of this result is shown in Fig. 5B.

\section{Discussion}

The vertebrate ELN gene has been analyzed in species ranging from chicken to human. In comparing the sequence divergence within functionally defined exons in the rat and human tropoelastin genes, it is clear that exons encoding hydrophobic domains diverge more rapidly than exons encoding cross-link domains (Boyd et al. 1991). Exon 34 encodes a hydrophobic domain; exon 35 encodes a potential cross-link domain. Both these exon domains are relatively conserved in sequence between bovine and rat tropoelastin. Significantly, however, both these exon-defined domains are present in all nonprimate vertebrate species analyzed, including chicken, suggesting that they predate both primate and mammalian radiation. The evolutionary radiation of mammals occurred about 200 million years ago (Macdonald 1993). Therefore, for over 200 million years, sequences defined by exons 34 and 35 were maintained in vertebrate tropoelastin genes. The conservation of this hydrophobic sequence and potential cross-link domain were therefore clearly important to the function of tropoelastin within vertebrate elastic tissues.

In contrast, exons 34 and 35 show little evolutionary stability during primate phylogeny. Nonhuman primates and human all diverged during the last 70 million years (Martin 1993). During this relatively short evolutionary period, two exons that had been maintained for over 200 million years were sequentially lost through what appears to be a series of Alu element-mediated recombination events. From the remnant of exon 35 detected in baboon genomic DNA, it would seem that mutational events resulted in the loss of exon 35 through the disappearance of constitutive splicing recognition signals. Continued recombination events at the $3^{\prime}$ end of the tropoelastin gene in the primate lineage that eventually developed into modern humans resulted in the additional removal of exon 34 .

One can only speculate as to the functional and evolutionary significance of the sequential loss of exons 34 and 35 during the development of primates. In several patients with a heritable vascular disorder, supravalvular 
A

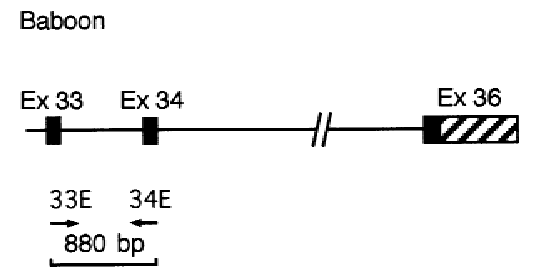

Human
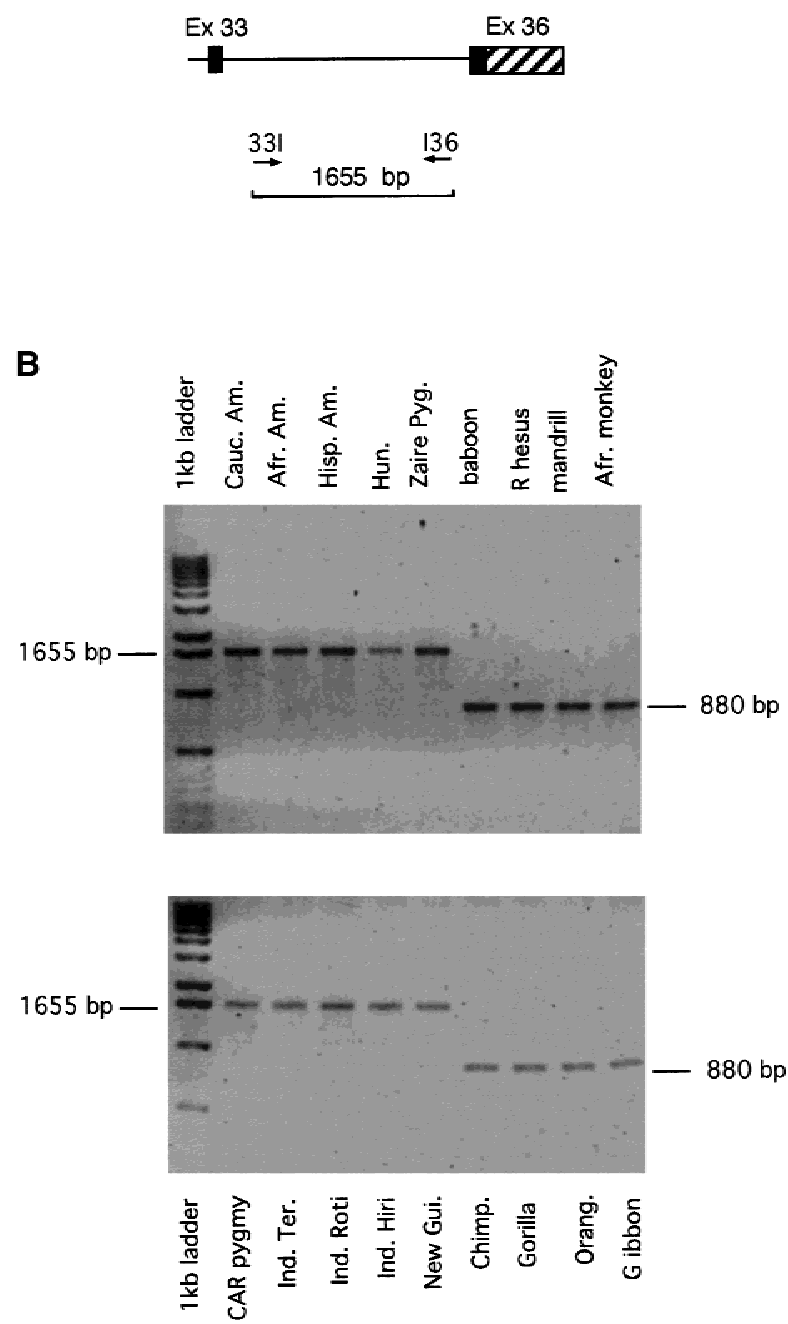

Fig. 5. Detection of species-specific configurations of the $3^{\prime}$ end of the ELN gene in human and other nonhuman primate genomic DNA. A The upper part depicts the PCR strategy for the detection of exon 33, intron 33, and exon 34 in nonhuman primate genomic DNA. Arrows denote the primers (33E and 34E) used for PCR, and the size of the expected PCR fragment is indicated as base pairs. The sequence of these primers and PCR reaction conditions are described under Materials and Methods. The lower part depicts the PCR strategy for the detection of intron 33 as characterized in human genomic DNA. The arrows represent the positions of the primers (33I and I36). The size of the expected PCR product is indicated as base pairs. B Representative examples of the recovery of PCR-derived DNAs from primates and different human populations. Cauc., Caucasian; Am., American; Afr., African; Hisp., Hispanic; Hun., Hungarian; Pyg., pygmy; Ind., Indonesian; Ter., Ternate; Gui., Papua New Guinea; CAR, Central African Republic; Chimp., chimpanzee; Orang., orangutan.
Table 1. A summary of the PCR screening of human and nonhuman primate DNA for the detection of size variations of the $3^{\prime}$ end of the ELN gene ${ }^{\mathrm{a}}$

\begin{tabular}{lcll}
\hline DNA source & $\begin{array}{l}\text { Number of } \\
\text { individuals }\end{array}$ & $\begin{array}{l}\text { Presence of } \\
\text { exon 34 }\end{array}$ & $\begin{array}{l}\text { Presence of } \\
\text { exon 35 }\end{array}$ \\
\hline chimpanzee & 3 & + & - \\
mandrill & 2 & + & - \\
gorilla & 2 & + & - \\
orangutan & 2 & + & - \\
gibbon & 3 & + & - \\
baboon & 36 & + & - \\
Rhesus monkey & 3 & + & - \\
Cyanomegalus & 2 & + & - \\
Total Primates & 53 & & - \\
Caucasian American & 76 & - & - \\
African American & 50 & - & - \\
Hispanic American & 50 & - & - \\
Hungarian & 46 & - & - \\
Zaire pygmy & 10 & - & - \\
C.A.R. pygmy & 7 & - & - \\
Indonesian & 10 & - & - \\
New Guinean & 24 & - & \\
Total Humans & 273 & & \\
\hline
\end{tabular}

a The lack of any size variation demonstrates that all nonhuman primates contained exon 34 but lacked exon 35, while all human DNA samples analyzed revealed the lack of both exon 34 and exon 35 .

aortic stenosis (SVAS), it has been shown that Alu element-mediated recombination events led to deletion mutations either within or involving the tropoelastin gene (Olson et al. 1995). While other elastic tissues such skin are affected by these tropoelastin gene deletions (Urbán and Csiszár, manuscript submitted), the overwhelming phenotype is a vascular disorder. In considering therefore selective advantages conferred through an Alu mediated loss of exons 34 and 35 during primate evolution, it is not unreasonable to speculate that perhaps alterations in vascular (particularly arterial) wall function, coincident with the evolution of primates, may have provided the selective advantage that led to the rapid loss of these two $3^{\prime}$ exons.

Acknowledgments. This work was supported in part by NIH RCMI Grant RR03061 and NSF Grant SBR-9610147 (M.A.B.). We are grateful to Drs. Katalin Csiszár and Zsolt Urbán for critically reading the manuscript.

\section{References}

Bashir MM, Indik Z, Yeh H, et al. (1989) Characterization of the complete human elastin gene. Delineation of unusual features in the 5'-flanking region. J Biol Chem 264:8887-8891

Boyd CD, Christiano AM, Pierce RA, Stolle CA, Deak SB (1991) Mammalian tropoelastin: multiple domains of the protein define an evolutionary divergent amino acid sequence. Matrix 11:235-241

Boyd CD, Pierce RA, Schwarzbauer JE, Doege K, Sandell LJ (1993) Alternate exon usage is a commonly used mechanism for increasing 
coding diversity within genes coding for extracellular matrix proteins. Matrix 13:457-469

Foster JA, Bruenger E, Gray WR, Sandberg LB (1973a) Isolation and amino acid sequences of tropoelastin peptides. J Biol Chem 248: 2876-2879

Foster JA, Gray WR, Franzblau C (1973b) Isolation and characterization of crosslinked peptides from elastin. Biochim Biophys Acta 303:363-369

Foster JA, Shapiro R, Voynow RC, Crombie G, Faris B, Franzblau C (1975) Isolation of soluble elastin from lathyritic chicks. Comparison to tropoelastin from copper deficient pigs. Biochemistry 14: 5343-5347

Indik Z, Yoon K, Morrow SD, et al. (1987) Structure of the $3^{\prime}$ region of the human elastin gene: Great abundance of Alu repetitive sequences and few coding sequences. Connect Tissue Res 16:197211

Kagan HM, Trackman PC (1991) Properties and function of lysyl oxidase. Am J Respir Cell Mol Biol 3:206-210

Macdonald DW (1993) The encyclopedia of mammals. Facts on File, p 895
Martin RD (1993) Primate origins: Plugging in the gaps. Nature 363: 223-234

Olson TM, Michels VV, Urbán Z, et al. (1995) A 30 kb deletion within the elastin gene results in familial supravalvular aortic stenosis. Hum Mol Genet 4:1677-1679

Pierce RA, Deak SB, Stolle CA, Boyd CD (1990) Heterogeneity of rat tropoelastin mRNA revealed by cDNA cloning. Biochemistry 29: 9677-9683

Raju K, Anwar RA (1987) Primary structures of bovine elastin a, b, and $\mathrm{c}$ deduced from the sequences of cDNA clones. J Biol Chem 262: $5755-5762$

Rucker RB, Gottlich-Rieman N, Tom K (1973) Properties of chick tropoelastin. Biochim Biophys Acta 317:193-201

Sambrook J, Fritsch EF, Maniatis T (1989) Molecular cloning. Cold Spring Harbor Laboratory Press, Cold Spring Harbor, NY, p 8.46

Sandberg LB, Weissman N, Smith DW (1969) The purification and partial characterization of a soluble elastin-like protein from copper-deficient porcine aorta. Biochemistry 8:2940-2945 